DOI: 10.23860/JMLE-2019-11-2-9

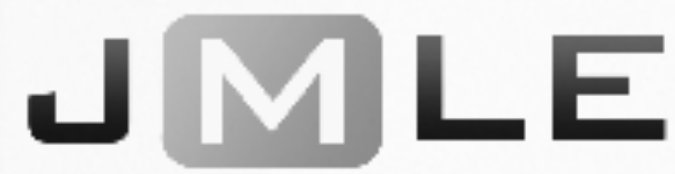

The National Association for Media Literacy Education's

Journal of Media Literacy Education 11 (2), 167 - 178

\title{
Teaching Adolescents to Communicate (Better) Online: Best Practices from a Middle School Classroom
}

\author{
Michelle Ciccone \\ Foxborough High School, Massachusetts USA
}

\begin{abstract}
Digital conversation spaces have the potential to generate powerful collective intelligence, but only when users are thoughtful, reflective, and have experience interacting with diverse ideas. To be able to engage in online conversational spaces in this way, though, is not inherent or natural: it must be practiced. This article will argue that it is essential to have adolescents practice engaging in challenging and professional conversations online with peers in classroom settings. Utilizing a New Media Literacy framework, this article will share impactful classroom practices that help adolescents develop effective online conversation skills. Essential to this pedagogy is a cycle of reflection, where students are asked to revisit their contributions to prior digital conversations and consider the impact that that prior contribution had on the conversation and the community. Asking students to reflect not on how to be kind (as most fear-based "digital citizenship" curriculum does) but rather on how contributions inform, persuade, and otherwise move the conversation forward, helps adolescents to develop a powerful online conversational presence.
\end{abstract}

Keywords: digital conversation; online conversation; digital citizenship; collective intelligence; Web 2.0; new media literacy

As a middle and high school technology integration specialist and digital literacy teacher, it is my duty to understand how adolescents use digital technologies, and to help them use them better. Through formal and informal conversation with my students (and through media stories and peer-reviewed research), I know that the experience with digital technologies that my students come to school with is extremely varied and complex, and that a teacher attitude of "our students know more than us" does not universally apply. I have also come to understand that many competencies that skilled digital technology users might take for granted are not naturally developed or necessarily mastered when picked up in context. Digital conversation skills are just such an example.

This article aims to accomplish two tasks: first, to make the case that developing productive and positive digital conversation skills belongs in K-12 curricula, and second, to help educators envision how to incorporate such activity into their own classroom. I believe that both aims are necessary contributions to the literature for several reasons. As will be explored below, a strategy that K-12 
schools in the US commonly currently employ when coaching young people through online participation is centered on "kindness," the message being that users of the Internet should first and foremost be kind to one another. When things go wrong - which, in a K-12 school context, can be a sexting or cyberbullying incident between students - schools will often involve the school resource police officers and focus the conversation on the violated associated laws. While online users are ideally not unkind in their interactions and should be aware of online harassment laws, I would argue that neither of these strategies prepare young people for the truly powerful potential of digital conversation and collaboration. What's more, in my experience as a middle and high school educator, 11-14 year olds do not internalize or access these messages as part of their personal digital literacy toolkit when they are on their own and interacting with others online. What I argue for here is that, just like we teach students how to write different genres of essays such as persuasive or argumentative, and just like we teach students communication and collaboration skills within a social-emotional learning context, we must also explicitly teach students to engage in digital conversation with one another, as a genre of communication and with specific productive purposes in mind.

Because of the fear that is already embedded in our school-based digital strategies, teachers that I encounter are wary of incorporating digital conversation in their coursework. What if students are mean to each other? What if they say something inappropriate? What if it gets out of control? Our experiences as adults interacting with others in toxic social media conversations lets us know that things could in fact go wrong, and teachers are left not knowing where to begin. But, by first articulating why participation in these digital collaboration spaces can be so powerful, the importance of effectively preparing young people for this participation becomes unavoidable. I will conclude this article with concrete classroom strategies for getting students to practice interacting with each other online.

\section{THE POTENTIAL FOR COLLECTIVE INTELLIGENCE ONLINE}

When people connect online, powerful things can happen. Users can forge true connections, both locally and globally: from affinity groups around trivial interests to organizing around social change movements. People turn to online communities for validation and support of ideas and identity, to gain access to once privileged information, and to amplify the voices of historically marginalized people. And though online communities do not replace or supersede the role of traditional, "offline" communities, Web 2.0 technologies-digital tools that encourage user participation and creation (DiNucci, 1999) - certainly provide resources that make connecting and sharing ideas easier. Web 2.0 tools such as meme generators, video sharing platforms, website builders, and social media help create spaces where "individuals are expected to actively co-construct and refine one another's ideas within certain media platform" (Lin, Li, Deng, \& Lee, 2013, p. 165). Today, the barrier to entry to ongoing online conversations is greatly reduced, if not nearly eliminated. 
Our digital media environment, deeply dependent as it is on these Web 2.0 technologies that encourage and enable sharing and interaction among users, builds on Blau's (2004) idea of "folksonomy," a concept which blurs the line between expert and non-expert. In Web 2.0 environments, "folk people can freely express their own ideas and extend/challenge others' (including experts') ideas... In this sense, both experts and nonexperts are authors of the media content" (Lin et al, 2013, p. 167). When users engage in conversation with one another on these Web 2.0 platforms, users generate what Jenkins, Purushotma, Clinton, Weigel, and Robison (2006) refer to as collective intelligence, which describes "the ability to pool knowledge and compare notes with others towards a common goal" (p. 4). A 2015 study of online communities found that "open, dynamic, and flexible systems empower groups to solve problems that are difficult to deal with for single individuals or organizations" (Mačiulienė \& Skaržauskienè, 2016, p. 1723). This holds powerful democratizing potential.

Unfortunately, we know that people are not always on their best behavior online, and these Web 2.0 environments can fall short of this collective intelligence potential. Users can be targeted by disinformation campaigns (Frum, 2018) and filter bubbles (Pariser, 2012) and disinformation can lead to violent extremism (Fisher \& Taub, 2018). Stanford researchers found that young adults are unable to identify untrue information online (Wineburg, McGrew, Breakstone, \& Ortega 2016). A 2018 Pew Research report found that nearly 60\% of teenagers have experienced at least one form of cyberbullying (Anderson, 2018), and that the psychological impact of these experiences can be long lasting (Wolke \& Lereya, 2015). The worst in human nature can leak out when users hide behind a screen.

Because of the opportunity for negative or potentially dangerous situations to occur, a sense of fear permeates public discourse generally and educational initiatives specifically meant to prepare young people for participation in digital spaces. For example, US First Lady Melania Trump's BE BEST initiative focuses public attention on the negative experiences young people can have on social media $^{1}$. And popular educational resources from organizations like Common Sense Media often position the Internet and digital technologies as dangerous, and young people must learn to be safe and protect themselves while using them ${ }^{2}$. In my experience working with many school districts and connecting with teachers from around the country, I have come to understand that the most common way that schools address adolescent participation in online spaces is through what is known as "digital citizenship education," which tends to have a hyper-focus on cyberbullying; young people are told to be kind when communicating with each other online. This is certainly important, but not the full story.

\footnotetext{
${ }^{1}$ https://www.whitehouse.gov/bebest/

${ }^{2}$ Common Sense Media, Scope \& Sequence: Common Sense K-12 Digital Citizenship Curriculum, Common Sense Education (n.d.). Retrieved from

https://www.commonsense.org/education/scope-and-sequence
} 
While a certain amount of concern for the physical and emotional safety of vulnerable populations, including adolescents, is a good and inevitable thing, an over-concern for this can place paralyzing restrictions on activities in primary and secondary schools. When school-based educational approaches focus so heavily on being kind online, the skills and habits users need to actively and positively contribute to spaces that build collective intelligence are neglected. For example, Mačiulienè and Skaržauskienė's 2016 study revealed that "communication culture, respect, and trust while communicating virtually" (p. 1723) were essential components of the most successful online spaces. The study also revealed that "a higher number of contributors to the creation of intelligence would yield a higher quality" (p. 1722) of the collective intelligence generated, and a "diversity in the source of ideas (Page, 2007) is the basic feature of successful collaboration initiatives because demographic, educational, or cultural diversity creates valueadding groups, organizations and societies due to access to different types of skills, talents, competencies, etc." (p. 1719). So to reap the maximum benefits of Web 2.0 tools that bring users together in dialogue around ideas, users must be able to navigate respectful and trust-building conversations that involve many, diverse voices.

These are absolutely skills and habits that K-12 schools can and should involve themselves in developing with students. These are a mix of technical skills, communication skills, and social-emotional competencies. Of course, schools already address these isolated skill groups; I argue that what is now needed is to contextualize these within digital conversation spaces. So how can digital conversation be taught? New Media Literacy has informed the development of a framework that has guided my classroom practice.

\section{USING NEW MEDIA LITERACY TO DEVELOP CLASSROOM PRACTICE}

New Media Literacy (NML) helps make sense of the fact that, by nature of the current Web 2.0 media environment, users today can at any point be both active or passive consumers and producers. Chen, Wu, and Wang (2011) created a framework for NML that makes two key distinctions, first between "functional" literacy - or the ability to utilize tools - and "critical" literacy — or the ability to critique, analyze, and participate. The second distinction is between consumption and prosumption. "Consuming" literacy can be defined as "the ability to access media message and to utilize media at different levels," while "prosuming" literacy is "the ability to produce media contents (e.g., messages and artifacts)" (Lin et al, 2013, 162). Koc and Barut (2016) operationalized Chen et al.'s NML framework, and named these four dimensions functional consumption (FC), critical consumption (CC), functional prosumption (FP), and critical prosumption (CP). NML educational models look to develop literacies across these four dimensions.

Koc and Barut developed a measurement tool comprising of multiple Likert scale-like items under each NML dimension. For the purposes of their study, Koc and Barut used their measurement tool to assess the NML capabilities of students 
at a university in Turkey. The researchers found that "participants have good levels of FC, CC, and FP whereas they have average level of CP" (p. 841). The researchers were not surprised that the university students they assessed had average levels of $\mathrm{CP}$, as "CP is the most complex and crucial part of NML" (ibid.). The researchers suggest that the "current generation of students should be supported in critical and active participation in new media platforms and creation of original media contents... School education should put more focus on how to produce and criticize media contents than how to access and understand them" (ibid.).

And so, to be able to contribute to the collective intelligence-building potential of online spaces, classroom practices must specifically address the skills associated with critical prosuming (CP). The items that measured CP in Koc and Barut's (2016, p. 839) measurement tool include:

- Influence others' opinions by participating [in] social media environments

- Make contribution to media by reviewing current matters from different perspectives (social, economical, ideological etc.)

- Collaborate and interact with diverse media users towards a common purpose

- Make discussions and comments to inform or direct people in the media

- Produce opposite or alternative media contents

- Design media contents that reflect critical thinking of certain matters

- Produce media contents respectful to people's different ideas and private lives

These items closely align with Lin et al.'s (2013) observation that in a Web 2.0 environment "individuals are expected to actively co-construct and refine one another's ideas within certain media platform" (p. 165), as well as Mačiulienė and Skaržauskienè's findings (2016) that collective intelligence is most successfully generated when users are able to engage in respectful dialogue that honors and encourages different perspectives. Building digital communication skills can be a way into developing these essential and too often neglected critical prosuming $(\mathrm{CP})$ skills. We teach communication skills explicitly in several contexts; it is time to teach digital conversation skills explicitly as well.

\section{BEST PRACTICES FROM A MIDDLE SCHOOL CLASSROOM}

What follows are classroom practices that take a critical prosuming $(\mathrm{CP})$ perspective on improving the online communication skills of adolescents. I have used the key principles highlighted here to develop a series of classroom activities that get adolescents thinking about how to build productive and healthy online communication spaces. These principles are rooted in the belief that CP skills can only be developed and refined through practice and active participation, and this can only occur in educational settings that reject the fear-based approach to digital citizenship. What follows was developed specifically for an 8th grade classroom, but these principles can be adapted to serve the needs of students older and younger. 


\section{Background}

I taught for three and a half years, from 2015-2019, in a middle school serving students in grades 6-8th in the metrowest suburbs of Boston in the US state of Massachusetts. My job title was Technology Integration Coordinator; half of my duties consisted of working with faculty across content areas to meaningfully integrate technology into classroom practice across the school, while the other half of my job was to teach a stand-alone, trimester-long digital literacy course. This course, which I named Technology for Learning and Life (T4L2), ran like a "specials" class akin to music, art, and physical education, and met twice a week for a total of about 22 classes each trimester. The content covered in this course stood independent of any content that was being covered in other parts of the school curriculum, but the skills and habits of thinking with technology I addressed in my curriculum was meant to be applicable throughout the students' studies and lives. I taught every student in the school each year, meaning that I taught every student when they were in 6th grade, then again when they were in 7th grade, and then again when they were in 8th grade. The digital conversation activities described here took place in my 8 th grade classrooms over the course of five trimesters, from the last trimester in 2017 to the end of the first trimester of the 2018-19 school year (concluding upon my departure from this school in early 2019). The bulk of the development of these activities occurred during the 2017-18 school year. During this school year, the demographics of the student population was as follows, as reported by the Massachusetts Department of Elementary and Secondary Education School and District Profiles ${ }^{3}$ :

- Race/ethnicity: 60\% white, 21.3\% Hispanic, 5.6\% Asian, 4.6\% African American, 0.8\% Native American, 0.3\% Native Hawaiian or Pacific Islander, and $7.6 \%$ multi-race/non-Hispanic

- Total in 8th grade: 115 / Total school enrollment: 395

- $39.7 \%$ classified as "high needs"

- $18.5 \%$ classified as economically disadvantaged

- $10.1 \%$ English is not the first language and 3.8\% classified as an English language learner

- $22.3 \%$ classified as a student with a disability

- Average class size: 19.9

My 8th grade T4L2 curriculum centered on the Internet: what it is and how it works. Students explored the biases and motivations built into the digital and physical infrastructure of the Internet. We covered controversial current events like net neutrality legislation, the development of self-driving cars, and the growing use of facial recognition software. Beginning in my second year teaching this course, I added periodic digital conversation activities. My goal in adding these activities was that my students would practice engaging in online conversation spaces within the confines of a safe and supportive classroom environment with opportunity for

\footnotetext{
${ }^{3}$ See http://profiles.doe.mass.edu/ for Massachusetts school profiles.
} 
peer and teacher feedback. I assessed each student's contribution by looking for the following in each digital conversation:

1. Student referred to reliable evidence to justify his/her point,

2. Student leaned into areas of disagreement by not just replying to comments they already agreed with, and

3. Student used an online conversational voice that was professional.

When assessing student contribution, I looked for growing fluency in these areas over time. As will be explored below, these points were unpacked with the help of student input. With these goals in mind, I created a sequence of activities that got students communicating with each other in digital spaces. I tinkered with and fine tuned these activities over the course of the five trimesters, ultimately engaging nearly 250 students in online conversations. For specific materials that I developed for these activities, visit http://bit.ly/DigConvoCiccone.

\section{Findings}

Below are what emerged as best practices in this curriculum development work. Specific activities can and should be altered to fit an educator's specific educational context, but I believe these best practices can be applied to a wide range of classroom scenarios to directly instruct students to be better communicators online.

Develop a sequence of activities. I ultimately developed a five lesson sequence, with five digital conversations occurring periodically over the course of 10-12 weeks. It is important that this work be understood to require multiple targeted experiences, because users will not become more productive online communicators as a result of a single lesson or one type of activity: the complex skills involved in powerful online conversations can be best demonstrated via a series of activities, so that the adolescent students themselves discover the utility of evidence-based, professional online conversations that move understanding forward. I believe that students themselves have to experience these things to be true in order to internalize these values and strategies.

Each digital conversation was centered around a high-interest conversational prompt that was related to curriculum content. Prompts included, "Should access to the Internet be a human right?" "Are you being brainwashed by the way that the Internet works?" "Do robots deserve rights?" and "Will increased automation make us more or less human?" The specific prompts used are not important, but the topics should be authentically (and developmentally appropriately) controversial, so as to recreate the online communication environment where users are engaged in conversation around charged topics. It is important to provide adolescents the opportunity to practice managing their emotion-based, gut impulse to reject ideas when participating in these challenging conversations. This is part of the essential social-emotional learning that must be embedded in this work.

Each activity followed the same general pattern: the conversational prompt is revealed, time is provided for students to develop a response to the prompt, access 
is given to the platform where the digital conversation will take place (more on this below), and then ample time is provided for students to engage in digital conversation with one another. Complexity is added with each activity. For the first activity, students are asked to simply compose an original post that is informative and persuasive; the dialogue occurs amongst the ideas posted. Commenting functionality is not added until the second activity, where students are directed to not only compose an informative and persuasive original post but to also comment at least twice on classmates' posts in a way that moves the conversation forward. The third activity involves sharing thoughts and questions while co-watching a video, mimicking the YouTube comment section. The final activities allow students to show growth in their digital conversational skills.

Play with logistics. There are several factors that can be experimented with depending on the specific classroom context, including:

- Platform used - Some ideas include Padlet (https://padlet.com/), which mimics a message board-type environment; VideoAnt (https://ant.umn.edu/), which allows for conversation during a video; and learning management systems such as Google Classroom, which allow for seamless integration into existing digital resource structures.

- Size of conversational groupings - Whole classes can be engaged in one online conversation or students can be divided into smaller groupings of 410 so that there are multiple digital conversations happening at once. Creating larger groupings for later activities could be an added layer of complexity, as students practice managing and integrating more and more ongoing ideas.

- The role of the teacher-The teacher can be an active, real-time online conversational partner or not.

- Synchronicity vs. asynchronicity of the online conversation-Depending on at-home technical capabilities, these digital conversations can happen during class time or for homework over the course of several days.

Decisions made about each of these factors will be dependent on classroom context such as age of students, devices available, and goals of the activities. Permutations are endless and all potentially fruitful.

Allow students to articulate what is valued. Determining what a productive contribution to the online conversation looks like should come directly from the students. My general strategy was to first have students contribute within the conversation, then have students reflect on and articulate what type of contribution in particular they appreciated the most. In other words, I wanted to make sure that the criteria for desired contribution we co-developed as a class was rooted in the actual experience of the class digital discussion, so that if things went wrong we could decide as a class that we did not want whatever happened to happen again. So, after participating in the first activity, at the end of class I turned editing privileges off for the platform (in this case we used Padlet), and had students take note of which posts they thought to be most informative or persuasive (not at this point unpacking those terms beyond a dictionary definition). First they took notes 
on their own, and then we created a list of characteristics as a class. Characteristics the students identified included:

- Used evidence

- Used professional language

- Well written

- Argument used is relatable

- Argument made sense

- The post asked questions that sparked critical thinking

After participating in the second activity where commenting was enabled, students were asked to identify the characteristics of comments that moved the conversation forward (again, not unpacking this as a class, but rather letting each student determine on their own what "moving a conversation forward" looks and feels like). Again, students reflected on this second conversation as observers after participating, first making notes individually and then sharing with the class. Characteristics the students identified included:

- Respectful of others' opinions

- Disagreed with ideas and didn't make it personal

- Represented a give and take of ideas

- Took the other person's ideas seriously

- Built on the original post's ideas

- On topic

- Not anonymous

- Comments were distributed equally amongst posts

- Brought together multiple perspectives

- Seemed to anticipate/consider the feelings and potential responses of others

These lists were turned into anchor charts and posted in the classroom so that they could be referred to during subsequent online conversation activities. I found that the lists that each class created were fairly similar from trimester to trimester, meaning that a majority of my 250 students valued the same characteristics of a digital conversation contribution.

The truly powerful thing is that these ideas came directly from the students; this was not a case of students being spoon-fed what a teacher wanted them to think. Without this classroom-based practice, there would not be this valuable shared experience of value-setting with online conversational partners.

Take time to reflect. Contributions to digital conversations can feel ethereal: a largely thoughtless comment on a friend's photo does not necessarily need to be revisited unless the comment stirs up some "drama." So within digital conversation spaces familiar to adolescents, unless something goes wrong, users are not routinely prompted to revisit their contribution to the online conversation. But a classroombased digital conversation activity sequence should make reflection on prior contributions central. In fact, reflection might be the most important principle that guides this work. Reflection can be done very simply, starting each digital 
conversation activity by looking back at the prior conversation and identifying (1) one way that you helped deepen your classmates' thinking and (2) what you could do better this time. I have found that with the distance of time students will be honest in assessing the impact of their contribution.

Remember that things will go wrong. Inevitably, when adolescents are communicating with each other in digital spaces, something will go wrong, and a student's contribution will not live up to the standards that the class has set. For example, a student may post memes or off-topic or even inappropriate comments; this happened at least once for each of my classes each trimester. When this inevitably happens, other students in the class can grow frustrated and demand that the disruptive student stop derailing the conversation. But we can see this an opportunity for learning rather than a situation to be avoided. It is likely that if a student is making disruptive contributions to a classroom-based digital conversation then they are also making disruptive contributions to online conversations they engage in outside of school. The face-to-face feedback that a student gets when derailing the classroom-based online conversation is invaluable, and may be the only unavoidable glimpse at the impact on online conversational partners that this type of disruptive contribution can have. It also may be the only chance that the student has to get feedback from an adult on the impact of their contribution. I strongly believe that it is productive and healthy to create classroom conditions under which young people can practice and safely make mistakes within online conversational spaces.

\section{Questions for Further Study}

The work described here successfully engaged nearly 250 students in digital conversations over the course of about one and a half years. This represents the work of just one teacher, though. I believe that the successes of this pedagogy warrant further study, particularly around the following open questions:

- All of the students who participated in the work described here knew each other offline as peers in the same classroom. How would these students engage in a digital conversation setting with conversational partners they did not know? Would this deepen the level of conversation or inspire silliness? Would 8th grade students be able to develop intellectual trust with unknown conversational partners?

- The findings detailed here are based on qualitative observation undertaken by the associated classroom teacher. What would quantitative data collection look like here? How can we quantify improvement of contributions to digital conversations? What might a quantitative observation tool look like?

- Though growth in the quality and productiveness of contributions to the digital conversations can be observed within the classroom context, a significant limitation is the inability to measure whether or not experiences in the classroom impacted behavior when students would interact with others in digital conversational spaces outside of the classroom, for example within gaming environments, social media, or message boards. This is 
beyond the scope of this paper and my impact as a middle school classroom teacher, but further study should be done on what instructional moves and curricular experiences have widest reaching impact on young people's digital contributions.

\section{Conclusion}

Our society benefits when people interact with one another online positively and productively in ways that build collective intelligence, generating ideas that individuals would never have been able to get to on their own. To do this, users must possess a set of skills that allows them to communicate ideas clearly and respectfully in these specific online conversational environments, and a set of dispositions that place value in diverse perspectives and prioritize reflection on personal contributions. To learn to fully participate online, classroom-based learning must include explicit practice participating in digital conversation spaces. This article shared classroom practices that build these digital conversation skills, but the classroom experience should not end here. Online conversation spaces will continue to evolve, and so the skills needed to successfully participate in these spaces will continue to change and evolve as well. Educators must abandon a sense of fear and dive into this important work.

\section{REFERENCES}

Anderson, M. (2018). A majority of teens have experienced some form of cyberbullying. Pew Research Center. Retrieved from http://www.pewinternet.org/2018/09/27/a-majority-of-teens-haveExperienced-some-form-of-cyberbullying/

Blau, A. (2004). The future of independent media. Deeper News, 10(1), 1-48.

Chen, D.-T., Wu, J., \& Wang, Y.-M. (2011). Unpacking new media literacy. Journal on Systemics, Cybernetics and Informatics, 9(2), 84-88.

DiNucci, D. (1999). Fragmented Future. Print, 53(4), 32, 221-222. Retrieved from http://darcyd.com/fragmented future.pdf

Fisher, M., \& Taub, A. (2018, April 25). How everyday social media users become real-world extremists. The New York Times. Retrieved from https://www.nytimes.com/2018/04/25/world/asia/facebookextremism.html

Frum, D. (2018, July 1). The great Russian disinformation campaign. The Atlantic. Retrieved from https://www.theatlantic.com/ideas/archive/2018/07/the-great-russiandisinformation-campaign/564032/

Jenkins, H., Purushotma, R., Clinton, K., Weigel, M., \& Robison, A. J. (2006). Confronting the challenges of participatory culture: Media education for the 21th century. White paper from the MacArthur Foundation. Retrieved from

https://www.macfound.org/media/article_pdfs/JENKINS_WHITE_PAPE R.PDF.

Koc, M., \& Barut, E. (2016). Development and validation of New Media Literacy 
Scale (NMLS) for university students. Computers in Human Behavior, 63, 834-843. https://doi.org/10.1016/j.chb.2016.06.035

Lin, T-B., Li, J.-Y., Deng, F., \& Lee, L. (2013). Understanding new media literacy: An explorative theoretical framework. Educational Technology \& Society, 16(4), 160-170.

Mačiulienè, M., \& Skaržauskienè, A. (2016). Emergence of collective intelligence in online communities. Journal of Business Research, 69(5), 1718-1724.

Page, S. E. (2007). The difference: How the power of diversity creates better groups, firms, schools, and societies. Princeton, NJ: Princeton University Press.

Pariser, E. (2012). The filter bubble: How the new personalized web is changing what we read and how we think. London: Penguin Books.

Wineburg, S., McGrew, S., Breakstone, J., \& Ortega, T. (2016). Evaluating information: The cornerstone of civic online reasoning. Stanford Digital Repository. Available at: http://purl.stanford.edu/fv751yt5934.

Wolke, D., \& Lereya, S. T. (2015). Long-term effects of bullying. Archives of Disease in Childhood, 100(9), 879-885. Retrieved from https://www.ncbi.nlm.nih.gov/pmc/articles/PMC4552909/ 